\title{
Improved Algorithms of Seismic Parameters Estimation and Noise Discrimination in Earthquake Early Warning
}

\author{
Naoyasu IWATA \\ Shunroku YAMAMOTO \\ Seismic Data Analysis Laboratory, Center for Railway Earthquake Engineering Research \\ Masahiro KORENAGA \\ Shunta NODA \\ Seismic Data Analysis Laboratory, Center for Railway Earthquake Engineering Research

\begin{abstract}
Improvements were made to the algorithms used for earthquake early warning, followed by tests to validate their performance for actual use. The upgraded algorithms are capable of producing more accurate and timely estimations of seismic parameters, compared with current algorithms. This new technique contributes to raising train operating safety during earthquakes. Another enhanced algorithm was devised for seismographs installed along railway lines, which makes them capable of discriminating between earthquake motion and train-induced vibrations. These improvements to the seismographs are expected to increase the reliability of earthquake early warning.
\end{abstract}

Keywords: earthquake early warning (EEW), seismic parameter, noise discrimination, train operation control, earthquake motion, train-induced vibration

\section{Introduction}

When the safty of railway facilities and running vehicles are threatened by strong ground motion during earthquakes, railway operators stop trains as soon as possible $[1,2,3]$. Since $\mathrm{P}$-wave propagation velocity is faster than $\mathrm{S}$-wave, $\mathrm{P}$-wave information is an effective source to stop trains rapidly. Japanese railways are equipped with systems which employ seismographs capable of automatically issuing $\mathrm{P}$-wave warnings $[4,5,6]$. The seismographs used for this earthquake early warning (EEW) system detect arrivals of P-wave, and then estimate seismic parameters, such as epicentral distance, back-azimuth and seismic magnitude, from passing P-wave waveform information. There are demands at present to improve the function of EEW systems, in order to raise railway safety during earthquakes. Thus a new algorithm for EEW systems was devised, to improve the accuracy of and shorten the time to obtain seismic parameters [7, 8]. Weak initial P-wave vibrations are used typically to estimate seismic parameters, thus it is necessary to discriminate clearly between earthquake motion and other vibrations. For seismographs installed along railway lines in particular, it is important to be able to distinguish train-induced vibrations so as to avoid false warnings. Seismographs in use today implement an algorithm which discriminates between different vibrations using the maximum amplitude ratio between the vertical and horizontal component motions [9]. Although this current technique is effective, a new algorithm was developed which also takes into account frequency characteristics to upgrade discriminatory ability. Introducing seismographs with the advanced algorithm for estimating seismic parameters and discriminating noises should raise the safety of train operations and the reliability of warnings during earthquakes.

\section{Data set in this study}

\subsection{Data set of the earthquakes}

The subject of this research is issuing warnings to trains running during earthquakes. The earthquakes used in the study were selected in consideration of their influence on railway facilities and running vehicles, and ensuring that their epicenters were not concentrated in a single specific region. In this study, 195 earthquakes were selected. Figure 1 shows the distribution of their epicenters. Figure 2 presents the relation between their seismic magnitude and the focal depth. The magnitudes varied from 4.5 to 9.0 , and the focal depths were less than $112 \mathrm{~km}$. Earthquake data for points within $200 \mathrm{~km}$ of the epicenters was collected from K-NET operated by NIED [10]. Far field earthquakes are not targets for rapid estimation of seismic parameters, which explains why the distance threshold from the epicenter was set to less than $200 \mathrm{~km}$. Figure 3 shows the histogram for epicentral distances. In this study, 10,171 seismic waveforms were used.

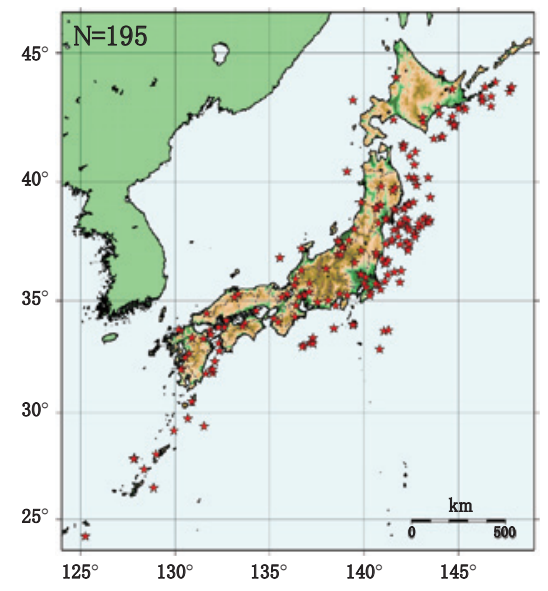

Fig. 1 Location of the epicenters 


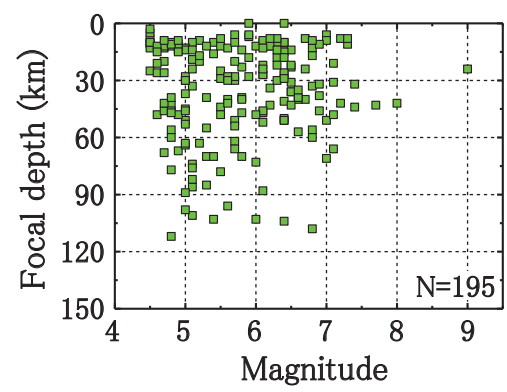

Fig. 2 Relation between seismic magnitude and focal depth

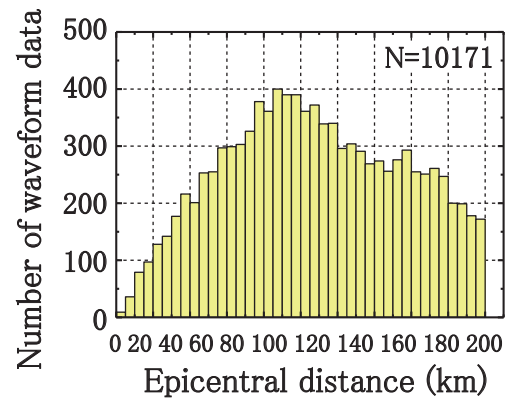

Fig. 3 Histogram of epicentral distances

\subsection{Data set for train-induced vibrations}

Traffic-induced and factory-induced vibrations may affect seismographs installed along railway lines. Among these vibrations, train-induced vibrations have the most influence on seismographs. Therefore, the target noises defined for this study were train-induced vibrations. Traininduced vibration data sets were obtained from seismographs installed near the railway line. Data was collected from 65 seismic stations, and 10,002 noise waveforms were studied. Train-induced vibration characteristics vary according to surface ground properties, and distance between tracks and seismographs, and so on. In order to evaluate the average discrimination tendency between earthquake motion and train-induced vibrations, data was handled in the same way.

\section{Improved algorithms for rapid estimation of seis- mic parameters}

Rapid warnings during earthquakes require seismographs to first detect $\mathrm{P}$-wave arrival, which must then estimate the location of the epicenter, including the epicentral distance and the back-azimuth. Finally seismographs need to estimate the seismic magnitude. This chapter describes the improved algorithms and their performance. The new algorithms are expected to shorten the time required to issue warnings from 2.0 seconds to 1.0 second.

\subsection{Detection of P-wave arrival}

When EEW seismographs estimate the seismic parameters based on initial P-wave information, they need to detect $\mathrm{P}$-wave arrival automatically in real-time. Cur- rent EEW seismographs use the STA/LTA method, which defines P-wave arrival time by cross matching timings of short term averages and long term averages, multiplied by a fixed constant of observed acceleration waveforms [11]. With this P-wave arrival detection technique, STA (Short Term Average) or LTA (Long Term Average) characteristics are important. To improve P-wave detection, especially for earthquakes where amplitude increases slowly with the initial $\mathrm{P}$-wave, the moving average parameter was redefined. Furthermore, a level-trigger method for detecting Pwave arrival, which activates when the amplitude exceeds a certain threshold, was also introduced to avoid missing strong motions. The level-trigger method is actuated when the STA/LTA method cannot detect the P-wave arrival. The threshold of this level trigger can be set at any value. Using the new detection method of P-wave arrival, the possibility of missing $\mathrm{P}$-wave arrival detection is reduced.

\subsection{Method for estimating epicentral distance}

Epicentral distance is found using the relation between the amplitude growth rate of the initial $\mathrm{P}$-wave and the epicentral distance. The current algorithm fits the initial 2 -second absolute acceleration waveform in the logarithm scale after $\mathrm{P}$-wave arrival to

$$
y(t)=B t \cdot \exp (-A t)
$$

where A and B are the regression coefficients. The B coefficient is then obtained by quantifying the amplitude growth rate of the initial $\mathrm{P}$-wave. This technique is called the $\mathrm{B}-\Delta$ method [4]. However waveforms arriving just after the $\mathrm{P}$-wave do not depend on magnitude, i.e. the scale of earthquake, therefore a simplified fitting equation for evaluating of the amplitude growth rate of the initial $\mathrm{P}$-wave is proposed, as follows

$$
y(t)=C t
$$

where $\mathrm{C}$ is the regression coefficient. When applying the simplified (2), the data length of calculation is shortened, since it can take the amplitude growth rate just after arrival of the P-wave. This proposed approach was called the C- $\Delta$ method [7]. Figure 4 shows the relation between data length value and the correlation coefficient. The values of $B$ and $\mathrm{C}$ correspond to the current and the proposed methods, respectively. The correlation coefficient is calculated using the epicentral distance from JMA (Japan Meteorological Agency) information. Because each value and corresponding epicentral distance have a negative correlation, it can be said that the estimation accuracy grows as the correlation coefficient approaches -1 . This figure shows that as opposed to the current method, the minimum correlation coefficient is reached using the new method with a shorter data length of calculation. These results confirmed that both speed and accuracy of estimation are improved using the C- $\Delta$ method. The time required for analyzing the data using this method is reduced to a quarter of what it was before.

Setting the time at which estimation of epicentral distance should begin. It was clear from comparisons that beginning calculations to estimate epicentral distance just after the P-wave arrival was not as accurate as starting this calculation after amplitude had increased by a cer- 
tain degree. The calculation commencement time for the new improved algorithm for rapid estimation of seismic parameters, was set, for the C- $\Delta$ method in particular, by applying the STA/LTA method. Figure 5 shows the relation between estimation accuracy and the fixed constant. Because the values of the logarithm error RMS (Root Mean Square) are an index for quantifying estimation error, lower values express higher estimation accuracy. From figure 5, the highest estimation accuracy was attained when the fixed constant was set at 4.0. The estimation starting time was delayed on average by approximately 0.18 seconds when 4.0 was set as the fixed constant, however, because of the shortened data length, the time required to produce an estimation was in fact still shorter than before. Figure 6 presents the epicentral distance calculated with JMA information and the coefficients $\mathrm{B}$ and $\mathrm{C}$. The value of $\mathrm{C}$ is calculated using the fixed constant 4.0, to determine the time when estimation calculation should start. It was confirmed that the accuracy of estimation of the epicentral distance was more accurate using the C- $\Delta$ method than the B- $\Delta$ method.

The linear equation in the current algorithm was applied to estimate the epicentral distances using the B- $\Delta$ method. However, since it was found that estimation accuracy gets better if including an internal damping member and in order to upgrade the algorithms, (3) was adopted to estimate the epicentral distance.

$$
\log _{10} C=P d 1 \cdot \log _{10} \Delta+P d 2+P d 3 \cdot \Delta
$$

where $\mathrm{C}$ is the calculated coefficient, $\Delta$ is the epicentral distance $(\mathrm{km}), \mathrm{Pd} 1$ to $\mathrm{Pd} 3$ are regression coefficients. Since the epicentral distance $\Delta$ cannot be obtained directly by (3), a grid search technique was used as a solution. Figure 6 shows the regression lines and curves using the B- $\Delta$ and C- $\Delta$ methods, respectively. Introducing the internal damping member reduced the logarithm error RMS by $5.7 \%$.

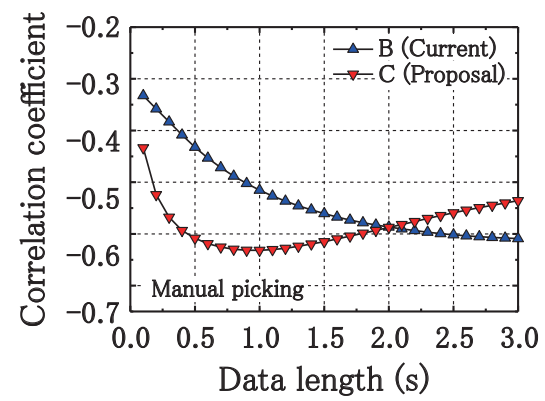

Fig. 4 Comparison of the B- $\Delta$ method and C- $\Delta$ method

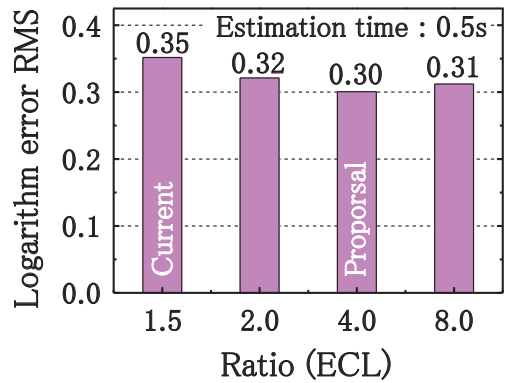

Fig. 5 Relation between estimation accuracy and the fixed constant

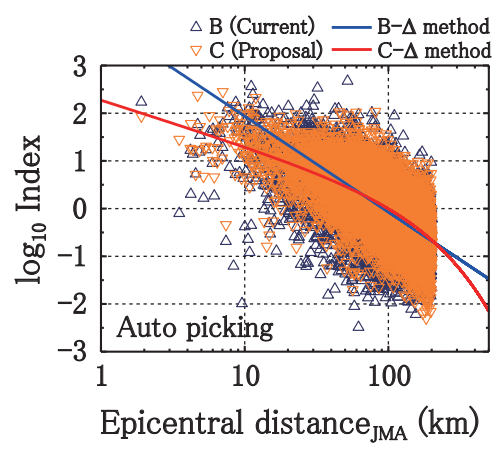

Fig. 6 Comparison of coefficient B and coefficient C

\subsection{Method for estimating back-azimuth}

In the current algorithm for estimating back-azimuths, data lengths of 1.1 second from P-wave arrival are used, together with principal component analysis. This technique is also known as the fixed window method. Figure 7 shows the relation between the various data lengths and the correlation coefficient. These correlation coefficients were calculated using the estimated back-azimuth and the calculated back-azimuth using JMA information. This figure demonstrates that the accuracy of the estimation increases as the correlation coefficient approaches 1 . The correlation coefficient was the highest when the data length was approximately 0.5 seconds. This confirms accuracy of the estimations improves when the data length is shorter than the current 1.1 seconds. Accuracy of the estimation was also higher when a data length of a half displacement wavelength after $\mathrm{P}$-wave arrival is used instead of the fixed time window. This new technique was called the variable window method [8]. Half wavelength data length can be detected when the displacement wave reaches the first zero-cross timing after the $\mathrm{P}$-wave arrival. Zero-cross timing, to estimate the back-azimuth by the principal component analysis, occurs between 0.3 seconds to 1.0 seconds after $P$ wave arrival. If no zero-cross point is detected during this period, a fixed data length of 0.5 seconds is adopted. Figure 7 also shows the correlation coefficient of the variable window method, and confirms that the proposed variable window method is better than the current fixed window method. The averaged data length by the variable window method is 0.58 second.

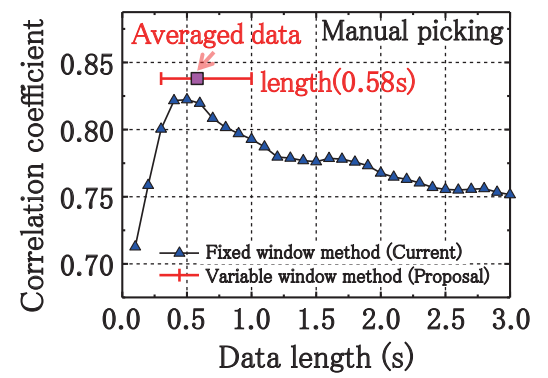

Fig. 7 Comparison of the fixed window and the variable window methods

\subsection{Method for estimating sersmic magnitude}

To estimate seismic magnitudes, the regression equa- 
tion is applied using the estimated epicentral distance calculated previously and the observed amplitude at that time. The displacement amplitude, obtained by integrating acceleration waveforms twice in the current algorithm, is applied. Figure 8 shows that the timing of the appearance of the maximum acceleration amplitude has a tendency to be statistically faster than the displacement amplitude. The averaged time difference is 2.9 second. The S-wave phase tendency is the same as $\mathrm{P}$-wave phase. Therefore, it is expected that if the estimation is based on the acceleration amplitudes this should speed up magnitude estimation. Figure 9 however shows that accuracy of estimations is higher when using displacement amplitudes rather than acceleration amplitudes. Thus, it is necessary to decide whether estimation accuracy is more important than immediacy. Immediate warnings are more effective for protecting the safety of Shinkansen trains running at high speed during earthquakes. Therefore, for the proposed algorithm the logical OR operation is adopted, which selects whichever has the higher value between acceleration magnitude and displacement magnitude.

Under the current method, in general, a maximum of three estimations can be sought for magnitude during the $\mathrm{P}$-wave. However, more detailed estimations can better preserve safety, and therefore, the new algorithm was improved to enable a maximum of 11 estimations.

In the current algorithm, linear equations are applied to estimate the magnitudes. Estimation accuracy is higher however when including an internal damping member. Equation (4) was therefore integrated into the new algorithm to estimate magnitude.

$$
M_{j}=P m 1 \cdot \log _{10} A+P m 2 \cdot \log _{10} \Delta+P m 3+P m 4 \cdot \Delta
$$

where $M_{j}$ is the JMA magnitude, $A$ is the value of the maximum amplitude (acceleration; $\mathrm{cm} / \mathrm{s}^{2}$, displacement; $\mathrm{cm}$ ), $\Delta$ is the epicentral distance estimated previously $(\mathrm{km})$, and $\mathrm{Pm} 1$ to Pm4 are the regression coefficients. By introducing

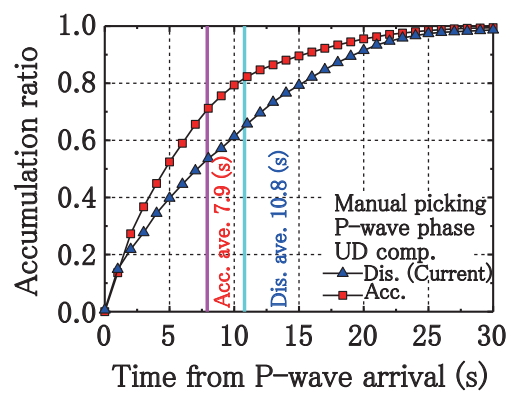

Fig. 8 Timing of the maximum amplitude appearance

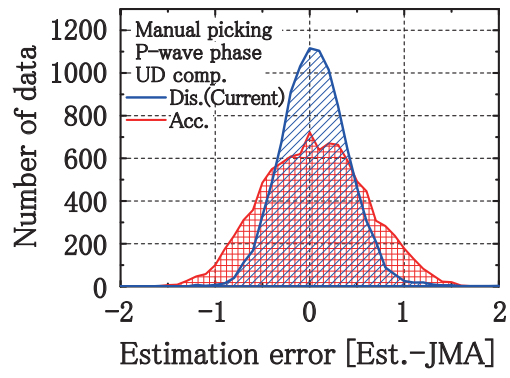

Fig. 9 Histogram of magnitude estimation errors the internal damping member, RMS errors for acceleration and displacement amplitudes are reduced by $4.0 \%$ and 1.5 $\%$, respectively.

\section{Improved algorithms for noise discrimination}

\subsection{Comparison seismic motion and train-induced vibration characteristics}

\subsubsection{Vertical and horizontal component amplitude ratio}

Initial seismic motion, or a $\mathrm{P}$-wave, is a compression wave. The angle of $\mathrm{P}$-wave incidence is generally almost vertical therefore predominant motion is composed almost entirely of vertical components on the ground surface. The current technique distinguishes seismic motion from traininduced vibrations, from the maximum amplitude ratio between the smoothed vertical component and the smoothed horizontal component. This index used in the current algorithm is known as VHmax [9].

Comparison of seismic motion and train-induced vibrations, using the data sets described in chapter 2 , shows that statistically the VHmax for seismic motions is over 1. Inversely, train-induced vibrations were statistically less than 1 . The current algorithm can therefore discriminate between these two types of vibration if the VHmax threshold is set appropriately.

\subsubsection{Frequency characteristics}

The vibration characteristics of train-induced vibrations are affected by the axle arrangement on a trainset, the running speed, inter alia. Observed train-induced vibrations have shown that their predominant frequency band is relatively high [12]. An example of normalized Fourier spectra of earthquake and noise from running trains is shown in Fig. 10. To compare frequency characteristics, each spectrum is normalized by the maximum amplitude of the Fourier spectrum. This figure shows that earthquake vibrations are relatively predominant in the low frequency band, and that the predominant frequency band for noise is higher than for earthquake vibrations. Using this difference in frequency characteristics is expected to improve discrimination between these vibrations.

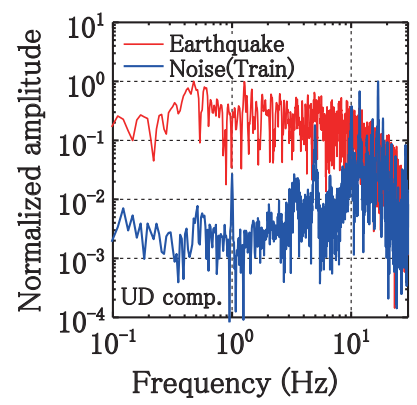

Fig. 10 Example of the normalized Fourier spectra 


\subsection{Proposal for a discrimination index considering frequency characteristics}

\subsubsection{Zero-cross method}

The zero-cross method is often used as simple technique for evaluating frequency characteristics in real time. This method counts the number of times the acceleration amplitude intersects the zero line per unit time, according to an index called Zc.

Zc calculations using vertical component vibrations to discriminate earthquake motion from noise showed that typically the number of times the train-induced vibrations crossed zero was higher than for earthquake motion. This confirms that the predominant frequency band for traininduced noise is relatively high. The relationship tendency found here between both vibrations therefore agrees with the result shown in Fig. 10.

\subsubsection{Approximate predominant period method}

Equation (5) was proposed as a techniques for evaluating the approximate predominant period $[1,13]$. This technique assumes that the target data section used for evaluating the predominant period is similar to a sine waveform. The index applied in this method is called Tc.

$$
T c=2 \pi \sqrt{\frac{\sum_{i=0}^{N_{t c}} v_{i}^{2}}{\sum_{i=0}^{N_{t c}} a_{i}^{2}}}
$$

where Tc is the approximate predominant period, $\mathrm{a}_{\mathrm{i}}$ is the vertical acceleration data $\left(\mathrm{cm} / \mathrm{s}^{2}\right), v_{i}$ is the vertical velocity data $(\mathrm{cm} / \mathrm{s})$ obtained by integrating the acceleration waveform once, $\mathrm{N}_{\mathrm{tc}}$ is the data length for calculating Tc defined as 3.0 second in this study and $i$ is a counter. The $v_{i}$ is calculated using a recursive filter in each sampling data.

As a result of the calculation of Tc and the statistical sorting, the value of Tc under train-induced vibrations is lower than for earthquake motion. Therefore, the approximate predominant period of train-induced vibrations is shorter than for earthquake motion.

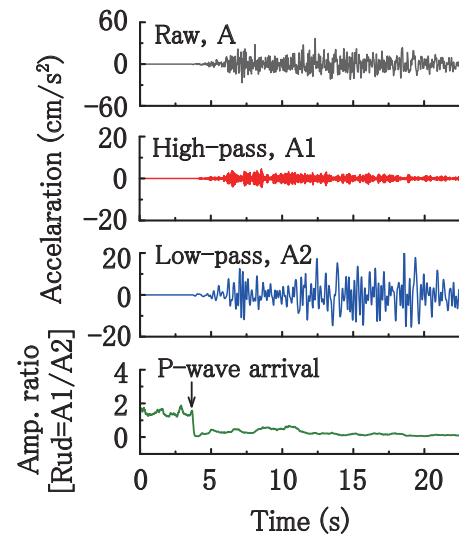

(a) Earthquake motion

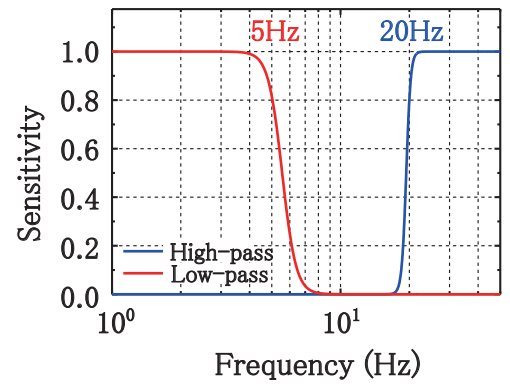

Fig. 11 Filtering frequency characteristics set for calculating the Rud

\subsubsection{Ratio of the frequency band}

A new method was proposed for discriminating vibrations. A calculation was made for each sample of the highpass and low-pass filtered waveforms applying the recursive filter in real time [14], using the ratio of those moving average of absolute amplitudes. This proposed new index is called Rud [15]. The cut-off frequency of the low-pass filter was set at $5 \mathrm{~Hz}$, and that of the high-pass filter at $20 \mathrm{~Hz}$, in consideration of the effective frequency range of seismographs in this study. Figure 11 shows the frequency characteristics for the Rud, while the equation for calculating the Rud is expressed as

$$
\operatorname{Rud}_{i}=\frac{\sum_{i=0}^{N_{\text {rud }}} a b s\left(a_{\text {high }}\right)_{i}}{\sum_{i=0}^{N_{\text {rud }}} a b s\left(a_{\text {low }}\right)_{i}}
$$

where Rud is the proposed index, $\operatorname{abs}\left(a_{\text {high }}\right)_{i}\left(\mathrm{~cm} / \mathrm{s}^{2}\right)$ is the absolute acceleration data after high-pass filtering, $\operatorname{abs}\left(\mathrm{a}_{\text {low }}\right)_{i}$ is the absolute acceleration data after low-pass filtering, $\mathrm{N}_{\text {rud }}$ is the data length of the moving average for calculating Rud, defined as 1.0 second in this study, and $\mathrm{i}$ is a counter.

Figures 12 (a) and (b) show the example of the time series for calculating the Rud. Figure 12 (a) shows earthquake motion, and (b) shows train-induced vibrations. The Rud value falls when the $\mathrm{P}$-wave is about to arrive whereas

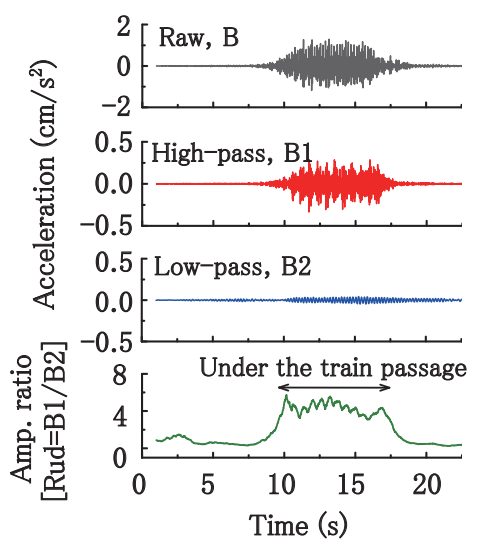

(b) Train-induced vibration

Fig. 12 Example of time series for calculating Rud 
it increases on arrival of a train. Statistical investigation of the Rud value shows that the Rud value for earthquake motion tends to be less than 1 .

\subsection{Verification and investigation of each discrimi- nation method}

Section 4.2 describes the indices used and the possibility of discriminating between earthquake motion and traininduced vibrations. This section investigates the thresholds for discrimination and recognition performance.

When an algorithm is used to automatically discriminate between earthquake motion and train-induced noise using the defined indices, faultless discrimination is impossible. The EEW algorithm occasionally misinterprets noise as an earthquake. This study therefore sets out to determine a threshold which can eliminate $90 \%$ of all train-induced vibrations. According to this unified threshold of train-induced noise, the discrimination rate of earthquake motion is able to be compared under the same condition. The thresholds set for each index defined in this study are shown in rows 1 to 4 in Table 1 , along with the discrimination rate. The table shows that discrimination rate achieved by certain indices does not reach $90 \%$. This discrepancy is due to adjustments of the threshold value to take into account possible practical application of the EEW system. Discrimination performance per individual index is shown in rows 1 to 4 of Fig. 13. Results show that the discrimination rate of earthquake motion per individual index, from highest to lowest, was VHmax, Rud, Tc and Zc.

Attempts were made to improve discrimination performance by combining indices, shown in rows 5 to 11 of Table 1 and Fig. 13. For example, OR (VH, Zc) represents the combination of VHmax and Zc in the logical OR operation. In this study each combination includes the conventional VHmax index along with combinations of the other indices. The threshold value following combination of the indices was determined to enable elimination of $90 \%$ of all train-induced vibrations, like with a single index. Discrimination rates of earthquake motion obtained after combining indices confirmed that discrimination performance with several indices was better than when using a single index. The discrimination rate obtained combining all indices $\mathrm{OR}(\mathrm{VH}$, $\mathrm{Zc}, \mathrm{Tc}, \mathrm{Rud}$ ) was found to not be the best solution, whereas the rate for $\mathrm{OR}(\mathrm{VH}, \mathrm{Zc}, \mathrm{Tc}, \mathrm{Rud})$ agreed with $\mathrm{OR}(\mathrm{VH}, \mathrm{Rud})$.
The table clearly shows that elimination rates were high in combinations including VHmax and Rud.

Figures 14 (a) and (b) are scatter diagrams for VHmax and Rud to evaluate their eliminatory ability. The red and blue dots denote earthquake and noise respectively. Figure 14 (a) shows the result of $\mathrm{OR}(\mathrm{VH}, \mathrm{Rud})$, where the elimination rate for earthquake motion is $87.4 \%$. The yellow areas express the discrimination domain in these figures. Figure 14 (b) shows results obtained using (7), and an earthquake motion elimination rate of $89.8 \%$.

$$
\log _{10} R u d \geq a \cdot \log _{10} V H+b
$$

where the coefficients a and $b$ are determined by grid search method so that the elimination rate for noise reaches $90 \%$ and reaches the maximum for earthquake motion. Since the method using (7) shows the best performance through off-line simulations, it was adopted and applied to improve the algorithm. Figure 13 demonstrates that the proposed method's performance in terms of discriminations improved by $7.4 \%$ against the conventional method.

Surface ground conditions or structural conditions etc., differ from site to site where seismographs are installed, while trains vary according to the type of line. It is therefore expected that train-induced vibrations characteristics will also vary accordingly. In order to be effective, the threshold value should thus be calibrated at each site where seismographs are installed. Average tendencies in this research were confirmed by handling all train-induced vibration data equally. Consequently, finding an effective method to determine thresholds suited to individual sites should be the subject for future studies.

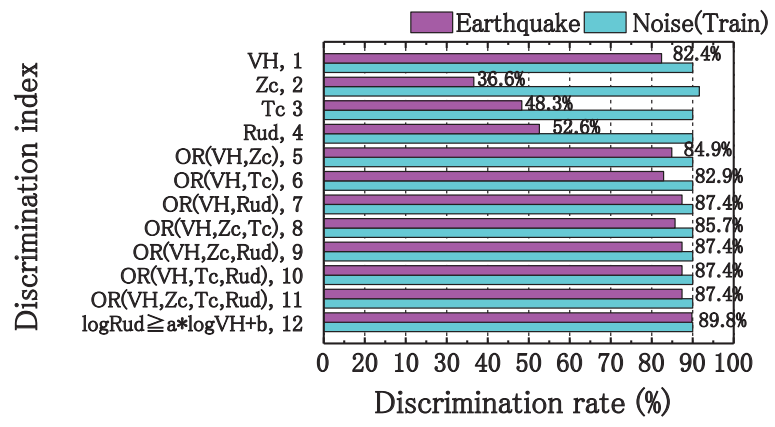

Fig. 13 Discrimination rate for seismic motion and traininduced vibrations

Table 1 Threshold and discrimination rate

\begin{tabular}{|c|r|c|c|c|c|c|c|}
\hline \multirow{2}{*}{ No. } & \multirow{2}{*}{$\begin{array}{c}\text { Discrimination } \\
\text { index }\end{array}$} & \multicolumn{5}{|c|}{ Threshold } & \multicolumn{2}{c|}{ Discrimination rate (\%) } \\
\cline { 3 - 8 } & VHmax & Zc & Tc & Rud & Earthquake & Noise(Train) \\
\hline 1 & VHmax & 1.29 & - & - & - & 82.4 & 90.0 \\
\hline 2 & $\mathrm{Zc}$ & - & 16 & - & - & 36.6 & 91.6 \\
\hline 3 & $\mathrm{Tc}$ & - & - & 0.271 & - & 48.3 & 90.0 \\
\hline 4 & $\mathrm{Rud}$ & - & - & - & 0.4 & 52.6 & 90.0 \\
\hline 5 & $\mathrm{OR}(\mathrm{VH}, \mathrm{Zc})$ & 1.20 & 47 & - & - & 84.9 & 90.0 \\
\hline 6 & $\mathrm{OR}(\mathrm{VH}, \mathrm{Tc})$ & 1.22 & - & 0.071 & - & 82.9 & 90.0 \\
\hline 7 & $\mathrm{OR}(\mathrm{VH}, \mathrm{Rud})$ & 1.07 & - & - & 6.0 & 87.4 & 90.0 \\
\hline 8 & $\mathrm{OR}(\mathrm{VH}, \mathrm{Zc}, \mathrm{Tc})$ & 1.16 & 43 & 0.053 & - & 85.7 & 90.0 \\
\hline 9 & $\mathrm{OR}(\mathrm{VH}, \mathrm{Zc}, \mathrm{Rud})$ & 1.07 & 53 & - & 6.0 & 87.4 & 90.0 \\
\hline 10 & $\mathrm{OR}(\mathrm{VH}, \mathrm{Tc}, \mathrm{Rud})$ & 1.07 & - & 0.016 & 6.0 & 87.4 & 90.0 \\
\hline 11 & $\mathrm{OR}(\mathrm{VH}, \mathrm{Zc}, \mathrm{Tc}, \mathrm{Rud})$ & 1.07 & 53 & 0.016 & 6.0 & 87.4 & 90.0 \\
\hline
\end{tabular}




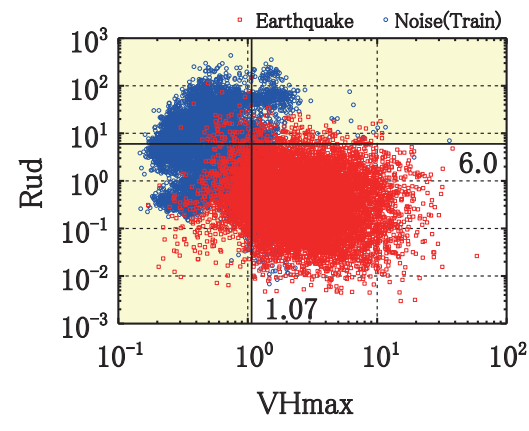

(a) OR(VH, Rud)

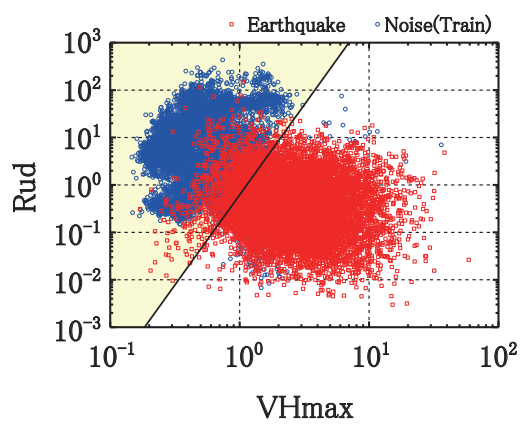

(b) Using equation (7)

Fig. 14 Discrimination condition

\section{Simulations using actual earthquake data}

To validate the results of rapid seismic parameter estimation in practice, the developed algorithm and determined parameters were applied to actual earthquake data. Waveform data was recorded at K-NET stations operated by NIED [10]. This offline simulation used typical parameters for railway EEW systems and recorded data from the "off-Noto peninsula earthquake $\left(\mathrm{M}_{\mathrm{j}} 6.9\right)$ " which occurred on March 25, 2007. Figures 15 (a) and (b) show the locations of the estimated epicenters by the current and the proposed method respectively. In this figure, the star marks the epicenter determined by JMA, and cross marks denote the epicenter estimated by EEW algorithms. Observation stations within $200 \mathrm{~km}$ from the epicenter were selected. The circle represents the region within a radius of $200 \mathrm{~km}$, and triangle marks denote the subject stations where the $\mathrm{P}$-wave was detected. As a result of the simulations, 66 stations were referred to for the current method and 76 stations for the proposed method. Comparison of both methods demonstrated that the proposed method has better P-wave arrival detection performance.

The estimated epicenter locations under the proposed method are more densely distributed around the JMA epicenter than the estimated locations under the current method. This confirms that the estimation accuracy for locating the epicenter can be improved by upgrading the algorithms. The calculated estimation RMS errors of seismic magnitudes were 0.97 and 0.72 for the current and proposed methods respectively, confirming that the proposed method is better than the current method for accuracy of magnitude estimation. A comparison of the speed at which early warnings were issued, showed that the shortest time under the proposed method was faster by 1.0 second than the current method. It is therefore expected that the speed at which warnings can be issued, will be improved.

\section{Summary}

This paper describes upgraded algorithms designed to produce more accurate and timely estimations of seismic parameters, while being able to eliminate train-induced vibrations, with a view to improving the safety and stability of train operations during earthquakes. In terms of the estimation of seismic parameters, this paper describes the improvement of algorithms for detecting P-waves, es-

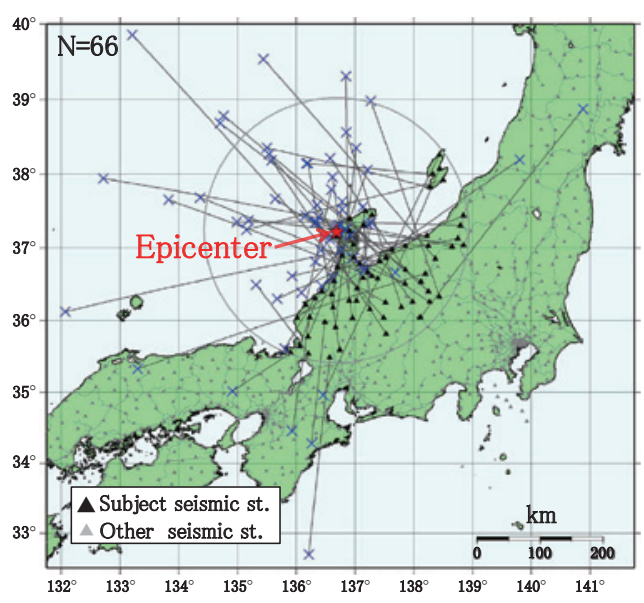

(a) The current B- $\Delta$ method and the fixed window technique

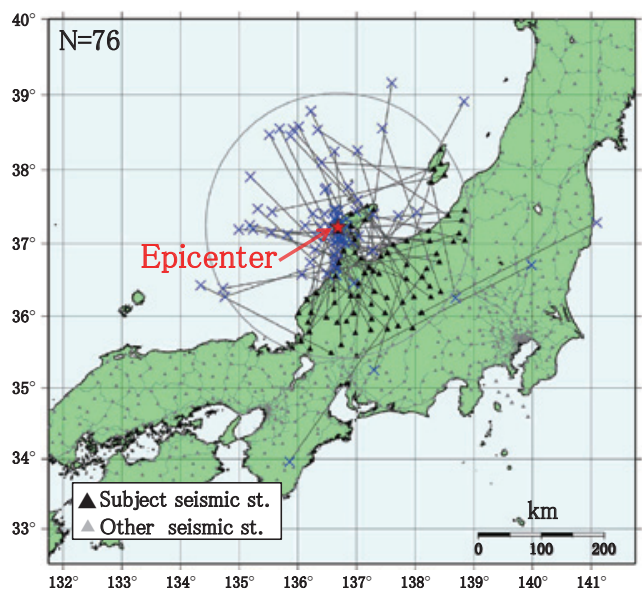

(b) The proposed $C-\Delta$ method the and the variable window technique

Fig. 15 Comparison of the estimated location of the epicenters

timating epicentral distance, back-azimuth and seismic magnitude. This algorithm is expected to raise estimation accuracy and speed if applied to an actual EEW system. A method is also proposed for combining the current VHmax index with a new proposed index, called the Rud, in order to raise the discrimination rate between earthquake motion and train-induced vibrations. This new method should, 
if applied, raise the discrimination performance of the algorithm.

A prototype seismograph was built using the upgraded algorithms, and successive operational tests have been carried out to confirm the performance of the algorithm in practice.

\section{Acknowledgment}

This report uses earthquake waveform data from KNET and KiK-net operated by NIED [10]. The map was drawn using Generic Mapping Tools [16]. The authors would like to express their sincere gratitude to all parties concerned.

\section{References}

[1] Nakamura, Y., "Research and development of intelligent earthquake disaster prevention systems UrEDAS and HERAS," Journal of structural mechanics and earthquake engineering, No.531/1-34, pp.1-33, Jan. 1996 (in Japanese).

[2] Ashiya, K., Sato, S., Iwata, N., Korenaga, M. and Nakamura, H., "Application of earthquake early warning information to earthquake alarm systems in railways," BUTSURI-TANSA, Vol. 60, No. 5, pp.387-397, 2007 (in Japanese).

[3] Yamamoto, S., and Tomori, M., "Earthquake early warning system for railways and its performance," Journal of JSCE, Vol. 1, pp.322-328, 2013.

[4] Odaka, T., Ashiya, K., Tsukada, S., Sato, S., Ohtake, K. and Nozaka, D., "A new method of quickly estimation epicentral distance and magnitude from a single seismic record," Bull. Seism. Soc. Am., Vol. 93, No. 1, pp.526-532, 2003.

[5] Iwahashi, H., Iwata, N., Sato, S. and Ashiya, K., "Practical use of earthquake quick alarm system," RTRI Report, Vol. 18, No. 9, pp.23-28, 2004 (in Japanese).

[6] Nakamura, H., Iwata, N. and Ashiya, K., "Statistical relationships between earthquake disaster and seis- mic parameters used for train operation control after earthquake," RTRI Report, Vol.19, No.10, pp.11-16, Oct. 2005 (in Japanese).

[7] Yamamoto, S., Noda, S. and Korenaga, M., "An estimation method of epicentral distance based on characteristics of P-wave initial envelope," RTRI Report, Vol. 26, No. 9, pp.5-10, 2012 (in Japanese).

[8] Noda, S., Yamamoto, S., Sato, S., Iwata, N., Korenaga, M., and Ashiya, K., "Improvement of back-azimuth estimation in real-time by using a single station record," Earth Planets Space, 64, 305-308, 2012.

[9] Sato, S. and Nakamura, H., "Development of general evaluation system for early earthquake detection technical skill," RTRI Report, Vol. 19, No. 10, pp.17-20, 2005 (in Japanese).

[10]Okada, Y., Kasahara, K., Hori, S., Obara, K., Sekiguchi, S., Fujiwara, H., and Yamamoto, A., "Recent progress of seismic observation networks in Japan Hi-net, F-net, K-NET and KiK-net," Earth Planets Space, 56, pp.15-28, 2004.

[11] Allen, R.V., "Automatic earthquake recognition and timing from single traces," Bull. Seism. Soc. Am., Vol. 68, No. 5, pp.1521-1532, 1978.

[12] Yoshioka, O. and Ashiya, K., "A dynamic model on excitation and propagation of shinkansen-induced ground vibrations," BUTSURI-TANSA, Vol. 48, No. 5, pp.299315, 1995 (in Japanese).

[13]Allen, R. M., and Kanamori, H., "The potential for earthquake early warning in Southern California," Science, Vol. 300, 2003, pp.786-789.

[14] Saito, M., "An automatic design algorithm for band selective recursive digital filters," BUTSURI-TANKO, Vol. 31, No. 4, pp. 112-135, 1978 (in Japanese).

[15] Iwata, N., Yamamoto, S. and Korenaga, M., “A method to discriminate noises from seismic motions for earthquake early warning," Proc. of the 14th Japan earthquake engineering symposium, pp.137-145, 2014 (in Japanese).

[16] Wessel, P., and Smith, W. H. F., "Free software helps map and display data," Eos Trans, AGU, Vol. 72 (41), p. 441, 1991.

\section{Authors}

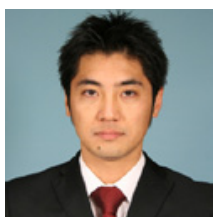

Naoyasu IWATA

Senior Researcher, Seismic Data Analysis Laboratory, Center for Railway Earthquake Engineering Research

Research Areas: Earthquake Engineering, Earthquake Disaster Prevention

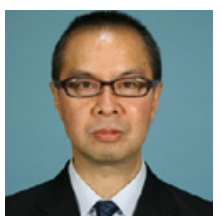

Shunroku YAMAMOTO, Dr. Eng.

Laboratory Head, Seismic Data Analysis Laboratory, Center for Railway Earthquake Engineering Research

Research Areas: Earthquake Engineering, Earthquake Disaster Prevention

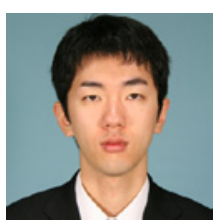

\section{Masahiro KORENAGA}

Assistant Senior Researcher, Seismic Data Analysis Laboratory, Center for Railway Earthquake Engineering Research Research Areas: Seismology, Earthquake Disaster Prevention

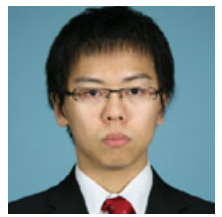

\section{Shunta NODA}

Assistant Senior Researcher, Seismic Data Analysis Laboratory, Center for Railway Earthquake Engineering Research Research Areas: Seismology, Earthquake Disaster Prevention 